\title{
PENELITIAN PENINGKATAN KETAHANAN KIKIS SOL KARET SEPATU OLAH RAGA
}

Oleh Herminiwati, Any Setyaningsih, Adi Slamet Supriyadi

\section{ABSTRACT}

Iif untie to improve the abrasion resistance of sport shoes rubber soles, 9 rubber cumpenud formula has been observed, with variation in using of calcium silicate and Aliminiви silicate as filler and naphtenic oil as softener. The result of this research hlintied that the best value of the abrasion resistance was $0,0485 \mathrm{~mm} 3 / \mathrm{kgm}$ and if filiniled the requirements of Indonesian National Standard 0171-1987-A. Canvas Hitein with rubber soles for sports. It constitutes the formula of 100 parts (by weight) if thatiant rubber, 25 parts of calcium silicate. 25 parts of aluminium silicate and 8 fanth of naphtenic oil. The usage of 50 parts of calcium silicate and aluminium (Hiti aie Illers with 8-10 parts of naphtenic oil didn't influence more on the hardness tinit Iif value fulfilled the requirements of Indonesian National Standard 0171-1987. A

\section{INTISARI}

(litiik meningkatkan ketahanan kikis sol karet sepatu olah raga, telah diteliti 9 firmalasi kompon karet dengan variasi penggunaan bahan pengisi kaisium silikat din iluminium silikat serta bahan pelunak minvak naptenik. Dari hasil penelitian diperuleh nilai ketahanan kikis terbaik sebesar $0,485 \mathrm{~mm} 3 / \mathrm{kgm}$ dan mememuhi Werataratan SNI 0171-1987-A, Sepatu Kanvas Dengan Sol Karet Untuk Olah Raga yнi! merupakan formulasi dengan menggunakan 100 bagian karet alam, 25 bagian fialinim silikat, 25 bagian aluminium silikat dan 8 bagian minyak naptenik FyHemaan 50 bagian bahan pengisi kaisium silikat dan aluminium silikat dengan (1) 10 hayiun bahan pelunak minyak naptenik tidak memberikan penganh yang besar Piila hekerasan, dan diperoleh nilai yang memenuhi persyaratan SNI, 0171-1987 A.

\section{PENDAHULUAN}

Sol adalah komponen sepatu olah raga yang sangat penting, karena menupakan bagian yang kontak langsung dengan tanah/lapangan, sehingga harus mempunyai ketahanan kikis yang baik dan memenuhi persyaratan. Ketahanan kikis yang rendah menyebabkan sol menjadi licin karena kembangan sol hilang dan menjadi rata, serta membahayakan karena mudah tergelincir. 
Berdasar hasil pengujian contoh-contoh sepatu olah raga dariberbagai merk, diperoleh hasil bahwa masih banyak dijumpai sol sepatu olah raga yang ketahanan kikisnya rendah dan belum memenuhi persyaratan SNI. 0171-1987-A : Sepatu Kanvas dengan Sol Karet Untuk Olah Raga, meskipun persyaratan sifat fisik lainnya telah dapat dicapai. Persyaratan ketahanan kikis (Grasselli) berdasar SNI. 01711987-A ditetapkan sebesar 1,0 $\mathrm{mm} 3 / \mathrm{kgm}$.

Ketahanan kikis yang rendah dapat dipengaruhi oleh penggunaan bahan pengisi maupun bahan pelunak baik dalam jumlah maupun jenisnya. Ada dua jenis bahan pengisi yang biasa digunakan untuk pembuatan barang-barang karet yaitu

1.Bahai pengisi aktif yang merupakan bahan yang bersifat sebagai pemerkuat (reinforcing filler) dan merupakan bahan pengisi yang penggunaannya dimaksudkan untuk meningkatkan sifat-sifat fisik barang karet sepert ketahanan kikis, ketahanan sobek, tegangan putus dan lain-lain, sebagai contoh adalah : karbon black.

Carbon black biasanya digunakan untuk pembuatan barang karet berwarna hitam, sedangkan untuk barang yang tidak selalu berwarna hitam seperti sol sepatu olah raga dapat digunakan bahan pengisi silika, aluminium silikat maupun kalsium silikat.

Walaupun silika murni adalah bahan pengisi yang sangat aktif karena mempunyai luas permukaan yang besar namun memberikan viskositas yang tinggi sehingga lebih sulit diproses. Kalsium silikat dan aluminium silikat selain lebih mudah diproses juga dapat ditambahkan dalam jumlah yang banyak serta memberikan vulkanisat yang lunak dan elastis. Penggunaan filler aktif dalam kompon karet alam umumnya sekitar 50 bagian perseratus bagian karet.

2.Bahan pengisi tidak aktif yaitu bahan yang tidak bersifat pemerkuat (non reinforcing filler) dimana penggunaannya terutama dimaksudkan untuk menekan harga, meningkatkan kekerasan dan sebagai bahan pembantu proses. Sebagai contoh adalah kaoline, talcum, chalk (calsium carbonat)

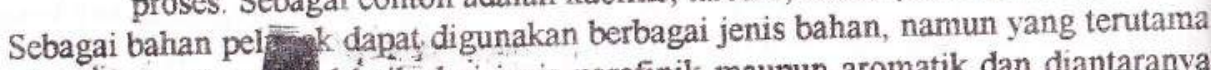
adalah minyak $m$ e. 1 baik dari jenis parafinik maupun aromatik dan diantaranya adalah minyak naptenik yang mempunyai sifat antara jenis parafinik dan aromatik Disamping ketahanan kikis, maka kekerasan juga dipengaruhi oleh banyaknya bahan pengisi dan pelunak yang dipakai. Standar kekerasan sol karet untuk sepatu olah raga ditetapkan sebesar 50-70 Shore A. Pada kompon karet alam penggunaan bahan pelunak perlu dipertimbangkan untuk menghindari kecenderungan terjadinya blooming atau migrasi. Penelitian penggunaan bahan pengisi magnesium karbonat untuk sol karet sepatu olah raga yang dilakukan oleh Asrilah dkk, 1990 belum mendapatkan hasil ketahanan kikis yang baik dan memenuhi persyaratan, iedangkan penelitian penggunaan bahan pengisi calsium karbonat untuk sol karet tepais kanvas oleh Titien Sayekti. S, 1991 juga masih menunjukkan hasil ketahanan kikin yams rendah dan belum memenuhi persyaratan. Oleh karena itu guna meninghatkan ketahana kikis dan mendapatkan kekerasan sol karet sepatu olah raga vane memenuhi persyaratan, perlu kiranya diteiti penggunaan aluminium silikat dan kakiam silikat pada berbagai level minyak naptenik.

\section{METODE PENELITIAN}

Bahan dan alat penelitian

I) Hahan penelitian meliput :

a Bahan baku karet alam : pale crepe

b Hahan pengisi : aluminium silikat dan kalsium silikat

C Bahan pelunak : minyak naptenik, parafin wax

d Inahan pencepat : Dibenzothiazole disulfit (MBTS)

Tetrametiltiuram (TMT)

- Bahan penggiat : $\mathrm{ZnO}$, asam stearat, Dietilenglikol (DEG)

fBahan pewarna : Trtan dioksida

15 Antioksidant : Penilbetanaptilamin (PBN)

hi Bahan pemvuikanisasi : belerang

1. Alat penclitian

a Two Roll Mill

b Hidraulic Press

c. Curometer

d Alat uji ketahanan kikis Grasselli

c. Durometer Hardness type A.

2. Cara penelitian

21 Penentuan perlakuan

Sebagai formula untuk pembuatan sol karet sepatu olah raga adalah seperti teriera dalam tabel 1 , 
sehingga diperoleh formulasi kompon penelitian sebagai berikut

\begin{tabular}{|l|l|l|l|l|l|l|l|l|l|}
\hline \multirow{2}{*}{ No. } & \multicolumn{1}{|c|}{ Bahan } & \multicolumn{10}{c|}{ F o r m u l s i } \\
\cline { 2 - 9 } & & I & II & III & IV & V & VI & VII & VIII \\
\hline 1. & Pale Crepe & 100 & 100 & 100 & 100 & 100 & 100 & 100 & 100 \\
2. & Asam stearat & 0,5 & 0,5 & 0,5 & 0,5 & 0,5 & 0,5 & 0,5 & 0,5 \\
3. & ZnO & 5 & 5 & 5 & 5 & 5 & 5 & 5 & 5 \\
4. & Kalsium silikat & 20 & 25 & 30 & 20 & 25 & 30 & 20 & 25 \\
5. & Aluminium sil. & 30 & 25 & 20 & 30 & 25 & 20 & 30 & 25 \\
6. & Naphtenic Oil & 8 & 8 & 8 & 8 & 8 & 8 & 8 & 8 \\
7. & Parafin & 0,5 & 0.5 & 0,5 & 0,5 & 0,5 & 0,5 & 0,5 & 0,5 \\
8. & PBN & 1 & 1 & 1 & 1 & 1 & 1 & 1 & 1 \\
9. & MBTS & 1 & 1 & 1 & 1 & 1 & 1 & 1 & 1 \\
10. & DEG & 2 & 2 & 2 & 2 & 2 & 2 & 2 & 2 \\
11. & TMT & 1 & 1 & 1 & 1 & 1 & 1 & 1 & 1 \\
12. & TiO? & 5 & 5 & 5 & 5 & 5 & 5 & 5 & 5 \\
13 & Belerang & 2 & 2 & 2 & 2 & 2 & 2 & 2 & 2 \\
\hline
\end{tabular}

\subsection{Pembuatan kompon}

Bahan baku karet dan bahan baku lainnya ditimbang dengan timbangan analitis Pale crepe terlebih dahulu dilunakkan dengan cara digiling sampai plastis pada suhu $40-50^{\circ} \mathrm{C}$. Kemudian tambahkan bahan-bahan lain berturut-iurut yakn pencepat, penggiat, antioksidan, plasticizer, pewarna, pengisi dan pelunak Penambahan bahan pelunak sebaiknya bersamaan dengan bahan pengisi atai sesaat setelah penambahan bahan pengisi agar waktu pencampuran tidal bertambah lama, karena penambahan bahan pelunak terlebih dahulu aka menghambat dispersi bahan pengisi dengan menurunnya shear forces.

Terakhir tambahkan belerang dan giling sampai homogen. Proses ini biasany berlangsung sekitar 20-30 menit. Kompon kemudian disimpan dalam ruan kondisi selama 24 jam pada suhu $27 \pm 2^{\circ} \mathrm{C}$ dengan kelembaban relatif $65 \pm 5 \%$ Selanjutnya diuji waktu vulkanisasi optimumnya dengan Curometer da kompon dicetak menjadi slab dengan menggunakan hidraulik pres pada tekana $150 \mathrm{~kg} / \mathrm{cm} 2$ dengan suhu dan waktu vulkanisasi seperti yang ditunjukkan al Curometer.

\subsection{Pengujian}

Pengujian ketahanan kikis dilakukan dengan menggunakan alar uji ketahana kikis Grasselli sesuai dengan metode SNI. 0171-1987-A, Sepatu Kanvas Dengar Sol Karet Untuk Olah Raga.
Adapun pengujian kekerasan dilakukan dengan menggunakan alat uji Drarameter lipe A sesuai dengan metode SNI yang sama.

\section{Amalisa Data}

Habif penelitian dihitung secara statistik dengan Completely Randomized Dewisin dan dilanjutkan dengan Duncan New Multiple Range Test.

\section{HASIL, PENELITIAN DAN PEMBAHASAN}

Cianif Penelitian

(Iiail ui ketahanan kikis dan kekerasan dari berbagai macam formulasi, disajikan Bada label berikut

Iabul 2. Ketahanan kikis dari berbagai level minyak naptenik dengan bahan pengisi kalsium silikat dan aluminium silikat.

\begin{tabular}{|c|c|c|c|c|c|c|}
\hline \multirow[t]{2}{*}{$\begin{array}{l}\text { Minyas } \\
\text { Haptenak }\end{array}$} & \multirow[t]{2}{*}{$\begin{array}{c}\text { Kalsiun } \\
\text { Silikat }\end{array}$} & \multirow[t]{2}{*}{$\begin{array}{l}\text { Aluminium } \\
\text { Silikat }\end{array}$} & \multicolumn{4}{|c|}{$\begin{array}{l}\text { Ketahanan Kikis ( } \mathrm{mm} 3 / \mathrm{kgm}) \\
\text { Ulangan }\end{array}$} \\
\hline & & & I & II & III & Rata-rata \\
\hline \multirow{3}{*}{11} & 20 & 30 & 0,317 & 0,593 & 2,163 & 1,024 \\
\hline & 25 & 25 & 0,421 & 0,453 & 0,582 & 0,485 \\
\hline & 30 & 20 & 0,508 & 0,587 & 0,446 & 0,514 \\
\hline \multirow{3}{*}{ (9) } & 20 & 30 & 0,656 & 0,468 & 0,527 & 0,550 \\
\hline & 25 & 25 & 0,420 & 0,713 & 0,424 & 0,519 \\
\hline & 30 & 20 & 0,506 & 0,519 & 0,540 & 0,522 \\
\hline \multirow{3}{*}{10} & 20 & 30 & 0,717 & 0,647 & 0,732 & 0,699 \\
\hline & 25. & 25 & 0,624 & 0,468 & 0,558 & 0,556 \\
\hline & 30 & 20 & 0,601 & 0,391 & 0,475 & 0,489 \\
\hline
\end{tabular}


Analisa sidik ragam (ANOVA) untuk perhitungan statistik ketahanan kikis adalah sebagai berikut

\begin{tabular}{|l|c|c|c|c|c|}
\hline Sumber Variasi & $\mathrm{dk}$ & JK & RJK & F Hit. & $\begin{array}{c}\text { F Tab. } \\
5 \%\end{array}$ \\
\hline Ulangan & 2 & 0,2746 & 0,1373 & & \\
Perlakuan & 8 & - & - & & \\
Kal. Sil./ Al. Sil & 2 & 0,3568 & 0,1774 & 1,7821 & 3,63 \\
Minyak Naptenik & 2 & 0,0963 & 0,0489 & 0,4837 & 3,63 \\
Kal. Sil/ Al. Sil.M.Naptenik & 4 & 0,2648 & 0,0062 & 0,6650 & 3,01 \\
Kekeliruan & 16 & 1,5927 & 0,0954 & & \\
& & & & & \\
\hline Total & 26 & 2,8430 & & \\
\hline
\end{tabular}

F hitung $<\mathrm{F}$ tabel $>$ berarti tidak ada perbedaan nyata $(\mathrm{P}<0,05)$ baik falsium silikat, aluminium silikat, minyak naptenik dan interaksinya.

Tabel 3. Kekerasan dari berbagai level minyak naptenik dengan bahan pengisi kalsium silikat dan aluminium silikat.

\begin{tabular}{|c|c|c|c|c|c|c|}
\hline \multirow{2}{*}{$\begin{array}{c}\text { Minyak } \\
\text { Naptenik }\end{array}$} & $\begin{array}{c}\text { Kalsium } \\
\text { Silikat }\end{array}$ & $\begin{array}{c}\text { Aluminium } \\
\text { Silikat }\end{array}$ & \multicolumn{4}{|c|}{$\begin{array}{c}\text { Kekerasan ( Shore A) } \\
\text { Ulangan }\end{array}$} \\
\cline { 4 - 7 } & & & I & II & III & Rata-rata \\
\hline \multirow{3}{*}{8} & 20 & 30 & 70 & 70 & 70 & 70 \\
& 25 & 25 & 65 & 65 & 65 & 65 \\
& 30 & 20 & 65 & 67,5 & 67,5 & 66,7 \\
\hline \multirow{6}{*}{9} & 20 & 30 & 60 & 60 & 60 & 60 \\
& 25 & 25 & 64 & 65 & 65 & 64,7 \\
& 30 & 20 & 70 & 70 & 70 & 70 \\
\hline \multirow{4}{*}{10} & 20 & 30 & 65 & 65 & 65 & 65 \\
& 25 & 25 & 65 & 65 & 65 & 65 \\
& 30 & 20 & 65 & 65 & 65 & 65 \\
\hline
\end{tabular}

nalika sidik ragam (ANOVA) untuk perhitungan statistik kekerasan adalah

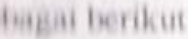

\begin{tabular}{|c|c|c|c|c|c|}
\hline Clamber Varass & $\mathrm{dk}$ & $\mathrm{JK}$ & RJK & F Hit. & $\begin{array}{c}\text { F Tab } \\
5 \%\end{array}$ \\
\hline Oínвe日 & 2 & 0,3519 & 0,17595 & & \\
\hline Terlah & 8 & - & - & & \\
\hline Kal Bil/AI sil & 2 & 31,1852 & 15,5926 & 55,6878 & 3,63 \\
\hline Minyak Naptenik & 2 & 31,1852 & 15,5926 & 55,6878 & 3,63 \\
\hline I ai hil/ AI Sil/M.Naptenik & 4 & 157,9259 & 39,4813 & 141,0046 & 3,01 \\
\hline Intelinaen & 16 & 4,4815 & 0,2800 & & \\
\hline 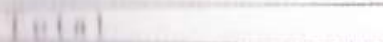 & 26 & 225,1297 & & & \\
\hline
\end{tabular}

hinun | I tubel ……> faktor kalsium silikat, aluminium silikat, minyak ihinil dan interaksinya ada perbedaan nyata $(\mathrm{P}<0,05)$.

menistahui beda nyata antar perlakuan, dilanjutkan dergan Duncan new

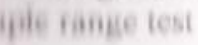

\section{athehasan}

Tulahiman kikis

Thinamatan ketahanan kikis (Grasselli) untuk sol karet sepatu olah raga Luthurkan SNI 0171-1987-A ditetapican sebesar maksimum 1,0 mm3/kgm

Aihinan hasil uji dari berbagai formulasi kompon sol yang diteliti menunjukkan Inilina umamnya formulasi kompon mempunyai nilai yang jauh lebih kecil dari 1 Humalan Nilai yang kecil menunjukkan bahwa sol karet mempunyai Dimhanan yang besar terhadap pengikisan.

Iini hetahaman kikis terendah adalah sebesar $0,485 \mathrm{~mm} 3 / \mathrm{kgm}$ yang merupakan Hmilani hompon dengan variasi kalsium silikat 25 bagian, aluminium silikat 1 hagian dan minyak naptenik 8 bagian. Adapun nilai ketahanan kikis (Ainini adalah sebesar $1,024 \mathrm{~mm} 3 / \mathrm{kgm}$ yang merupakan hasil formulasi Hininin dengan variasi kalsium silikat 20 bagian, aluminium silikat 30 bagian lan minyak napienik 8 bagian.

lai ini dapat discbabkan karena kalsium silikat merupakan bahan pengisi yang Whih thit dibanding aluminium silikat sehingga penggunaan bahan pengisi ani lebih akuf dalam jumlah yang lebih banyak yakni 25 bagian disertai whambahan jumah pelunak yang tepat yakni 8 bagian akan meningkatkan tahanan kikis yang lebih besar pula. Berdasarkan hasil analisa statistik, tidak wilipat beda nyata $(\mathrm{P}<0,05$ ) untuk ketahanan kikis dari beroagai formula 


\section{DAFTAR PUSTAKA}

kompon dan ini menunjukkan bahwa kalsium silikat, aluminium silikat dan minyak naptenik dapat meningkatkan ketahanan kikis sol karet.

\subsection{Kekerasan}

Persyaratan kekerasan untuk sol karet sepatu olah raga menurut SNI. 01711987-A, ditetapkan sebesar 50-70 Shore A.

Kekerasan sol karet merupakan persyaratan penting karena akan menunjang pengounaannya, sebab sol yang keras, kaku, dan tidak lentur tidak dapat berfungsi sebagaimana mestinya, demikian pula sebaliknya sol yang terlalu lunak tidak dapat meredam benturan seperti yang diharapkan.

dari hasil pengujian kekerasan terhadap berbagai formulasi menunjukkan bahwa kombinasi variasi bahan pengisi 20-30 bagian dengan bahan pelunak 8-10 bagian tidak memberikan perbedaan nilai kekerasan yang besar.

Hal ini menunjukkan bahwa kekerasan lebih dipengaruhi oleh jumlah bahan pengisi yang ditambahkan dari pada jenisnya.

Untuk semua formulasi yang diteliti, jumlah bahan pengisi yang ditambahkan adalah sama yaitu sebesar 50 bagian untuk 100 bagian bahan karet, yang merupakan kombinasi dari kalsium silikat dan aluminium silikat

Adapun penambahan bahan pelunak sebesar antara $8-10$ bagian, walaupun dalam perhitungan statistik menunjukkan ada beda nyata $(p<0,05)$, namun jumlah tersebut belum cukup memberikan pengaruh yang besar terhadap nilai kekerasan.

Dari hasil uji kekerasan diperoleh nilai sebesar 60-70 Shore A, yang berarti kesemuanya memenuhi persyaratan yang ditetapkan.

\section{KESIMPULAN}

Bahan pengisi kalsium silikat, aluminium silikat dan bahan pelunak minyak naptenik dapat meningkatkan ketahanan kikis sol karet sepatu olah raga.

Formulasi kompon yang mempunyai nilai ketahanan kikis yang terbaik yakn sebesar $0,485 \mathrm{~mm} 3 / \mathrm{kgm}$ adalah : Pale crepe 100 bagian, Asam stearat 0,5 bagian, $\mathrm{ZnO} 0,5$ bagian, Kalsium silikat 25 bagian, Aluminium silikat 25 bagian, Minyak naptenik 8 bagian, Paraffin wax 0,5 bagian, PBN 1 bagian, MBTS 1 bagian, DEG 2 bagian, TMT 1 bagian, Titan dioksida 5 bagian dan Belerang 2 bagian.

3.Penggunaan minyak naptenik sebesar $8-10$ bagian dengan jumlah bahan pengisi sebesar 50 bagian tidak menunjukkan pengaruh yang besar terhadap kekerasan
I HeHan thamdardisasi Nasional, 1987

(1)i $01 / 1.1087$-A, Sepatu Kanvas Dengan Sol Karet Untuk Olah Raga.

J Chafanan W, Tahun 1989

Ciatiny I w linology Handbook, Houser Publisher, Munich Vienna. New York.

I Mankanco, Tahun 1981

Tomifumaders Handbook, International Edition. Monsanto Rubber Chemical Thusien, Akron, Ohio $\$ 4313$

1 Aif Hoard of Consultants and Engineers, Tahun 1978

lititine Iechnology and Manufacture SBP Chemical Series No.65. Small Business Gihication. New Delhi

A thewari Noeseno, Tahun 1979

Thioman Pengujian Sifat Fisika Barang Jadi Karet, Menara Perkebunan 1520547. 